\title{
Reaction of monkey mothers to long-term separation from their infants
}

\section{GORDON D. JENSEN, REGIONAL PRIMATE RESEARCH CENTER AND DEPARTMENT OF PSYCHIATRY, UNIVERSITY OF WASHINGTON, Seattle, Wash. 98105}

Five pigtailed monkey mothers (Macaca nemestrina) were separated from their six-month-old infants. Mothers reacted initially with agitation. Eighteen days after separation several behavioral measures suggested depression. Two months after separation all measures returned to preseparation levels and showed no change after infants were reunited with their mothers.

Both monkey and human infants show similar response patterns to separation from their mothers, namely, initial agitation followed by depression (Bowlby, 1960; Kaufman \& Rosenblum, 1967; Seay \& Harlow, 1965; Seay, Hansen, \& Harlow, 1962; Jensen \& Tolman, 1962). Almost no attention, however, has been given to the effects of infant separation on non-human and human mothers. Seay, Hansen, and Harlow (1962) separated rhesus mothers from their infants by a Plexiglas partition and observed both mothers and infants during a three-week period. The mother's initial emotional response of agitation appeared to be less intense and of shorter duration than the infant's. Studies have shown that when reunited, monkey mothers and infants go through a period of intensified closeness; this behavior was observed following separations as brief as a few hours or as long as three weeks (Bowlby, 1960; Kaufman \& Rosenblum, 1967; Seay \& Harlow, 1965; Seay, Hansen, \& Harlow, 1962; Jensen \& Tolman, 1962).

The purpose of our study was to determine the effects of prolonged separation (two months) on mother monkeys. Based on a previous study of brief separation $(2 \mathrm{~h}$ ) (Jensen \& Tolman, 1962) and on pilot observations of longer separations (two weeks) we hypothesized that mothers, like infants, would undergo an initial period of agitation, followed by a period of depression lasting about two to three weeks.

Method. The subjects were five pigtailed monkey mothers $(M$. nemestrina), whose infants had been born about six months earlier. All were members of an established social group formed approximately a year prior to the beginning of the experiment. This group of 21 monkeys, resembling a natural macaque group in terms of sex and age of the members, was housed in a $32 \times 30 \times 8 \mathrm{ft}$ compound and had been left undisturbed prior to this experiment.

The five mothers were observed through one-way vision windows. A check list was used and the following behavior categories were recorded if they occurred during any 30-sec interval: Walk, locomoting a total of $6 \mathrm{ft}$ or more; Sit, sitting quietly for a period of $5 \mathrm{sec}$ or more and not engaged in any active behavior; Lie, Lying down for a period of 5 sec or more and not engaged in any active behavior; Groom other, grooming another animal (not own infant) for $5 \mathrm{sec}$ or more; Act other, interacting with other animals (not own infant) in any way other than grooming: aggression, sexuality, handling, mouthing, escaping, avoiding (each behavior lasting at least 1 sec); Groom self, grooming self for longer than $5 \mathrm{sec} ;$ Act self, self-directed activity other than grooming: mouthing, handling and scratching (each lasting at least $1 \mathrm{sec}$ ); Vocalize, any kind of vocalization; Close, in close-touching body contact with another animal (not own infant), sitting or lying for a total of $5 \mathrm{sec} ;<3 \mathrm{ft}$, closer than $3 \mathrm{ft}$ (but not in close body contact) to other animal (not own infant) for a total of $5 \mathrm{sec} ;>3 \mathrm{ft}$, farther than $3 \mathrm{ft}$ from any animal (not own infant) for a total of $5 \mathrm{sec}$. Three 10-min observations of each mother, randomly scheduled between 2 and 5 PM, were made and constituted a block for purposes of analysis. Baseline observations were taken prior to the separation (Block 1).

One hour before Block 2 each mother was caught with a net and manually separated from her infant. The infants were taken to another floor and placed together in a large cage. A third block of observations was made four days after the separation and subsequent blocks were made at approximately weekly intervals up to 58 days after separation. Block 7 was a sham manipulation of the mother; that is, the mothers were caught and handled in the same way as when originally separated. The final observations (Block 8) were made immediately after the infants were reunited with their mothers approximately two months after separation. Two infants died during the period of separation; one from ingestion of cage bedding material (Pele-cel) and the other from unknown cause.

Results and Discussion. Blocks of data (1) were compared to test specific hypotheses. Data from Block 2 (the day of separation) were included for analysis because we predicted agitation on this day and Block 5 (18 days after separation) was selected for statistical comparison because by that time measures suggested depression. Because all mothers went into estrus about one month after separation, a variable likely to affect some of the behaviors scored, no observations were made between the 30th and 53rd day of the study. Blocks 6 to 8 , beginning two months after separation, when all mothers were in the quiescent phase of estrous cycle, constituted the final observation period of this experiment and these blocks were considered comparable to the preseparation baseline.

Mothers responded to separation from their infants by an immediate period of agitation. Compared with the baseline (Block 1), the following three measures were significantly greater on the day of separation (Block 2): active behavior (2) $(p<.025)$, walking $(\mathrm{p}<.01)$, and vocalization $(\mathrm{p}<.005)(3)$ (Fig. 1). The

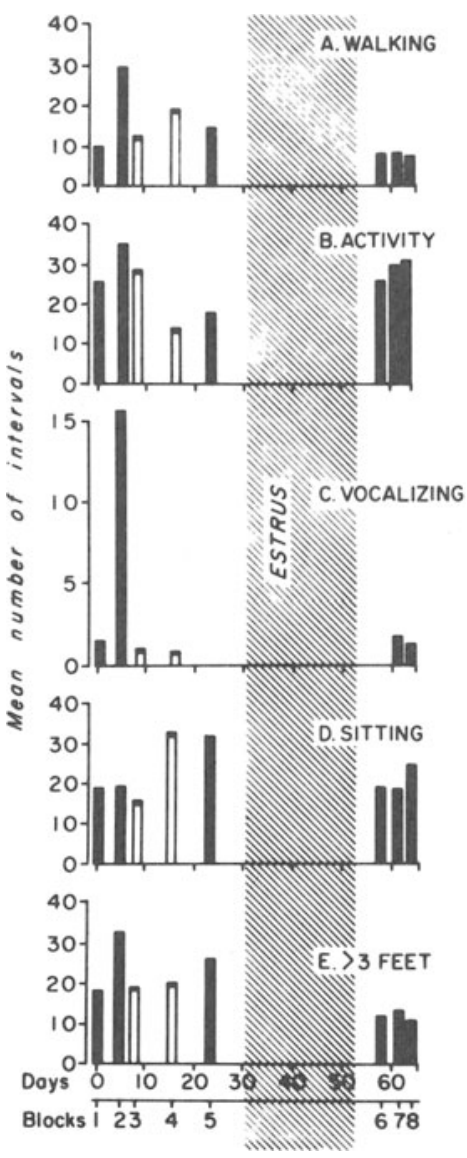

Fig. 1. Mean number of time intervals in which five different activities occurred are related to observation Blocks 1.8 (see text). Measures were derived from check list data. Solid bars indicate those blocks tested statistically. 
significant increase in the measure "farther than $3 \mathrm{ft}$ " $(\mathrm{p}<.01)$ suggests that the mothers were also less sociable during the immediate postseparation period. With one exception, all mothers repeatedly climbed on the fence near the door where their infants had been removed, searching and vocalizing.

On the day following separation most mothers still made repeated trips to the door, but were not as active or vocal as they had been on the previous day. Two mothers sniffed at the only remaining infant in the group. By the third day after separation no unusual behavior of the mothers was noted.

The hypothesized depressed behavior was evident from inspection of data taken 18 days after separation (Block 5). The measure of quiet sitting behavior was greater then than at any time ( $p<$ .025) suggesting decreased activity. This is confirmed by the low level of active behavior noted in this block (Fig. 1). The small but significant increase in the measure "farther than $3 \mathrm{ft}$ " $(\mathrm{p}<.025)$ suggests withdrawal, one of the most common symptoms of depression in man. The monkeys did not show peculiar behavior patterns such as hunched-over sitting posture and "slow motion" movement as has been reported for infant monkeys during periods of prolonged separation.

The sham manipulation (Block 7) did not produce agitation. However, a relatively small, but statistically significant $(p<.01)$ increase in selfdirected behavior occurred and may have been a reflection of distress produced by the capturing procedure.

The results of this study led us to postulate three phases of maternal response to separation: (1) agitation, (2) readjustmentdepression, (3) recovery. Agitation was dramatic but relatively brief in these mothers. Readjustment-depression was mild and more subtle than the depression described for infants (Bowlby, 1960; Kaufman \& Rosenblum, 1967; Seay \& Harlow, 1965). We expected to see more striking evidence of depression in the mothers in this study, based on our earlier observations of pigtailed mothers and infants living in individual cages and then separated. These latter mothers were slow in their motor behavior, were hyporeactive to strangers and ate poorly. The theory that group associations may mitigate maternal depression needs investigation by further study of mothers living in more isolated conditions. In the present study, recovery was evident two months after separation and measures which suggested depression were no longer apparent at that time.

\section{REFERENCES}

BOWLBY, $\mathbf{J}$. Grief and mourning in infancy and early childhood. Psychoanal. Stud. Child., 1960, 15, 9.

KAUFMAN, I. C., \& ROSENBLUM, L. A. Depression in infant monkeys separated from their mothers. Science, 1967, 155, 1030.

SEAY, B., \& HARLOW, H. F. Maternal separation in the Rhesus monkey. J. nerv. ment. Dis., 1965, 140, 434.

SEAY, B., HANSEN, E., \& HARLOW, H. F. Mother-infant separation in monkeys J. child Psychol. Psychiat., 1962, 3, 123.

JENSEN, G. D., \& TOLMAN, C. W. Mother-infant relationship in the monkey (Macaca nemestruna): The effect of brief separation and mother-infant specificity. J. comp. physiol. Psychol., 1962, 55, 131.

\section{NOTES}

1. Analysis of variance for repeated measures was used. Hypothesized differences between block means were tested by orthogonal comparisons. A one-tailed test was used.

2. Active behavior: a measure of only those intervals in which one or more of the following behaviors occurred: Walk, Groom Other, Act Other, Groom Self, Act Self, and Vocalize. No inactive behavior such as Sitting Quietly occurred during these intervals.

3 , One mother (E) differed in general response from the other four mothers. As she was the lowest ranking animal in dominance order of the entire group, and all other mothers were in the upper half of the dominance hierarchy, her behavior could be expected to be somewhat discrepant from that of the others. A test for non-additivity of treatment effects was made and was significant for the vocalization measure. The corrected $\mathrm{F}$ for the difference in block means was then significant at $\mathrm{p}<, 005$. (A. L. Edwards, Experimental Design in Psychological Research, Rinehart \& Company, Inc. (rev. ed.), 1960, p. 165.)

4. Research supported by Public Health Service Grant No. FR 00166 from the National Institutes of Health.

5. The author is grateful to Ruth A. Bobbitt for statistical consultation and to Jacklyn Wolfheim, Linda Alderson, and Betty Gordon for technical assistance. 